\title{
Rendimento, composição química e atividades antimicrobiana e antioxidante do óleo essencial de folhas de Campomanesia adamantium submetidas a diferentes métodos de secagem
}

\author{
OLIVEIRA, J.D. ${ }^{1 ;}$ ALVES, C.C.F. ${ }^{\prime}$ MIRANDA, M.L.D. ${ }^{2}$; MARTINS, C.H.G. ${ }^{3} ;$ SILVA, T.S. ${ }^{3 ;}$ AMBROSIO, M.A.L.V.; \\ ALVES, J.M.'; SILVA, J.P. ${ }^{1}$ \\ 1'Instituto Federal de Educação, Ciência e Tecnologia Goiano, Câmpus Rio Verde, Rodovia Sul Goiana, km \\ 01, Zona Rural, Caixa Postal 66, Rio Verde, GO, 75901-970, Brasil. IInstituto Federal de Educação, Ciência e \\ Tecnologia do Sul de Minas Gerais - Câmpus Pouso Alegre, 37550-000, Pouso Alegre - MG, Brasil. ${ }^{3}$ Universidade \\ de Franca, Laboratório de Pesquisa em Microbiologia Aplicada, LaPeMa - Avenida Dr. Armando Salles de Oliveira, \\ 201, 14404-600, Franca, São Paulo, Brasil. *Autor para correspondência: mayker.miranda@ifsuldeminas.edu.br
}

RESUMO: Campomanesia adamantium é muito utilizada na medicina popular no tratamento de hipertensão, reumatismo e diabetes. Objetivou-se com o presente trabalho avaliar o rendimento, a composição química, e as atividades antimicrobiana e antioxidante do óleo essencial de folhas de $C$. adamantium submetidas a diferentes métodos e tempos de secagem. O delineamento utilizado foi inteiramente casualizado, com oito tratamentos e três repetições. O óleo essencial foi extraído por hidrodestilação das folhas e analisado por CG-EM. O tipo de secagem das folhas de $C$. adamantium influenciou no teor e na composição química do óleo essencial. Os constituintes espatulenol, óxido cariofileno e germacreno-B apresentaram maior concentração na maioria das procedências avaliadas. O óleo essencial das folhas de $C$. adamantium apresentou moderada atividade antibacteriana em relação a todos os micro-organismos testados. A atividade antioxidante se deu empregando-se o método de redução do radical estável DPPH, sendo observada fraca atividade antioxidante por meio do ensaio utilizado.

Palavras-chave: Campomanesia adamantium, Myrtaceae, secagem, sesquiterpenos, atividade antibacteriana, DPPH.

\begin{abstract}
Content, chemical composition and antimicrobial and antioxidant activities of the essential oil from leaves of Campomanesia adamantium submitted to different drying methods. C. adamantiumis widely used in popular medicine for thetreatment of hypertension, rheumatism and diabetes. This study looked to evaluate the essential oil yield, the chemical composition and the antimicrobial and antioxidant activities of the essential oil from leaves of C. adamantium. A completely randomized design was used with eight treatments and three replications. The essential oil obtained by hydrodestillation of the leaves was analyzed by GCMS. The results show that the drying type and the processing of the leaf influence the content and chemical composition of the essential oil. The compounds spathulenol, caryophyllene oxide and germacrene-B have higher concentrationsin mostorigins. The essentialoil from theleaves of C.adamantiumshowed moderate bacterial activityagainst all tested microorganisms. The antioxidant activity was determined by the methods of reduction of the DPPH stable radical. The antioxidant activity was weak in the test used.
\end{abstract}

Key words: Campomanesia adamantium, Myrtaceae, drying, sesquiterpenes, antibacterial activity, DPPH.

\section{INTRODUÇÃO}

Campomanesia adamantium é uma planta pertencente à família Myrtaceae, e esta família compreende cerca de 4000 espécies e 130 gêneros distribuídos por todos os continentes, exceto na Antártica. É uma das famílias botânicas mais características da flora brasileira, apresentando significativo interesse econômico para o Brasil (D’Angelis et al., 2014; Paula et al., 2008).

O potencial medicinal de muitas plantas pertencentes à família da planta em estudo tem

Recebido para publicação em 29/10/2015

Aceito para publicação em 06/05/2016

10.1590/1983-084X/15_206

Rev. Bras. PI. Med., Campinas, v.18, n.2, p.502-510, 2016. 
sido cientificamente comprovado, como a atividade anti-reumática, antidiabética, antimicrobiana, diurética e reguladora do sistema digestivo (Serafin et al., 2007). Plantas desta família são produtoras de substâncias com propriedades biológicas importantes e destacam-se também como produtoras de óleos essenciais (Lima et al., 2006).

Muitos óleos essenciais são largamente empregados na indústria química e farmacêutica (Maia et al., 1987) e o processo de secagem de plantas produtoras de óleos essenciais deve ser criterioso devido à volatilidade dos constituintes químicos que compõem estes óleos. Deste modo, a definição de metodologias de secagem mais apropriadas para cada espécie é necessária, visando a assegurar os teores de substâncias ativas.

É descrito na literatura que a secagem natural e artificial da biomassa foliar de Piper hispidinervum levou a alteração na composição química de monoterpenos e sesquiterpenos do óleo essencial, demonstrando que a concentração de alguns constituintes diminuía enquanto de outros como, por exemplo, do safrol aumentava (Machado et al., 2013).

C. adamantium (Cambess.) O. Berg é uma planta conhecida popularmente como guavira, gabiroba ou guabiroba e possui porte arbustivo podendo medir de 0,5 a $1,5 \mathrm{~m}$ de altura (Lorenzi et al., 2006). C. adamantium se destaca por ser utilizada na alimentação, medicina e para pasto apícola, (Vieira et al., 2006). Na alimentação humana, seu fruto pode ser ingerido in natura, ou na forma de doces, sorvetes, geleias, licores, aguardentes e sucos (Gogosz et al., 2010).

Estudos fitoquímicos prévios com $C$. adamantium revelaram a presença de monoterpenos e sesquiterpenos em óleo essencial de frutos e flores e flavanonas e chalconas nas folhas (Vallilo et al., 2006a,b; Coutinho, 2008; Coutinho et al., 2011).

O objetivo deste trabalho foi avaliar o teor, a composição química e as atividades antibacteriana e antioxidante do óleo essencial de folhas de $C$. adamantium submetidas a diferentes tipos de secagem.

\section{MATERIAL E MÉTODOS}

\section{Coleta do material vegetal}

As folhas de C. adamantium foram coletadas na região de Rio Verde nas propriedades da Universidade de Rio Verde, nas coordenadas $17^{\circ} 47^{\prime} 14,8^{\prime \prime}$, W $50^{\circ} 57^{\prime} 59,1^{\prime \prime}$ e uma altitude de 769 $\mathrm{m}$, entre às 07 e 08 horas da manhã em outubro de 2014. O material vegetal foi identificado e uma amostra encontra-se depositada no Herbário Jataiense Professor Germano Guarin Neto sob registro $n^{\circ}$ HJ 6561.

\section{Secagem do material vegetal}

As folhas de C. adamantium foram submetidas a dois métodos de secagem: secagem artificial a $40^{\circ} \mathrm{C}$ em estufa com circulação forçada de ar e a secagem natural à sombra. Foram colocadas $100 \mathrm{~g}$ das de folhas em papel craft, realizado em triplicata, em seguida as folhas foram colocadas em estufa de circulação forçada de ar a $40^{\circ} \mathrm{C}$. O mesmo procedimento foi simultaneamente realizado à sombra nas bancadas do laboratório, protegidas do sol e chuva. Os tempos de secagem avaliados foram: $0 ; 0,25 ; 0,50 ; 1 ; 3 ; 5 ; 8$ e 16 dias.

\section{Determinação da umidade}

Utilizaram-se $6 \mathrm{~g}$ de folhas frescas picadas, as quais foram emersas em $70 \mathrm{~mL}$ de cicloexano. Após o processo de destilação, realizado por $3 \mathrm{~h}$ a temperatura de $100{ }^{\circ} \mathrm{C}$ quantificou-se o volume de água presente no material, por meio do coletor de vidro tipo Dean Stark. A umidade foi calculada considerando-se o teor de água contido em $100 \mathrm{~g}$ da amostra (Pimentel et al., 2006).

\section{Extração dos óleos essenciais}

A extração do óleo essencial de $100 \mathrm{~g}$ de folhas, em triplicata, de $C$. adamantium submetidas a diferentes tempos de secagem à sombra e em estufa foi realizada através do método de hidrodestilação, em aparelho Clevenger, durante quatro horas a partir da ebulição (Siqueira et al., 2011). O óleo essencial foi extraído da fase aquosa através de partição líquido-líquido utilizando diclorometano. Foram realizadas três lavagens do hidrolato com três porções de $10 \mathrm{~mL}$ de diclorometano. O óleo essencial extraído foi seco com sulfato de sódio anidro, acondicionados em pequenos frascos de vidro âmbar e mantidos sob refrigeração até posterior análise por CG-EM.

\section{Análise do óleo essencial}

O óleo essencial foi diluído em hexano e submetido à análise em cromatógrafo em fase gasosa modelo QP-5000 da Shimadzu ${ }^{\circledR}$ com detector por espectrometria de massas (CG-EM). A análise foi realizada com coluna capilar de sílica fundida, modelo DB-5 (30 m de comprimento x 0,25 $\mathrm{mm}$ de diâmetro interno $\times 0,25 \mu \mathrm{m}$ de espessura de filme) da Shimadzu ${ }^{\circledR}$, sendo utilizado como gás de arraste hélio $(\mathrm{He})$ em fluxo de $1,0 \mathrm{~mL} / \mathrm{min}$. A injeção em modo Split 1:20 foi realizada com injetor a 240 ${ }^{\circ} \mathrm{C}$. A temperatura do detector foi de $270{ }^{\circ} \mathrm{C}$ e o forno de 60 a $180^{\circ} \mathrm{C}$ a $3{ }^{\circ} \mathrm{C} / \mathrm{min}$. Para a detecção foi aplicado a técnica de impacto eletrônico a 70 eV. Foram realizadas três repetições para o óleo essencial analisado. 


\section{Identificação dos constituintes do óleo essencial}

A determinação da composição química do óleo essencial foi realizada através dos espectros de massas, obtidos por CG-EM. Os compostos voláteis foram identificados por comparação dos tempos de retenção obtidos com os tempos de retenção de hidrocarbonetos lineares (série homóloga de $\mathrm{C}_{10}-\mathrm{C}_{29}$ ) que foram coinjetados com a amostra. Os índices de retenção e os espectros de massas foram comparados com dados da espectroteca Wiley e Nist e da literatura (Adams, 2001).

\section{Analise estatística}

O delineamento experimental foi inteiramente casualizado em esquema fatorial $(2 \times 8)$, sendo dois métodos de secagem e oito tempos de secagem, com três repetições. Para a análise dos dados foi utilizada a análise de variância e as médias foram comparadas pelo teste de Tukey a 5\% (Silva \& Azevedo, 2002) de significância usando programa ASSISTAT versão 7.7 beta.

\section{Cepas bacterianas}

As cepas testadas foram obtidas junto a American Type Culture Collection (ATCC, RockvilleMD, EUA). Os micro-organismos usados na avaliação da atividade antibacteriana do óleo essencial de $C$. adamantium foram: Streptococcus mitis (ATCC 49456), Streptococcus mutans (ATCC 25175), Streptococcus sanguinis (ATCC 10556), Streptococcus sobrinus (ATCC 33478) e Bacteroides fragilis (ATCC 25285).

\section{Atividade antibacteriana}

Os valores de concentração inibitória mínima (CIM) do óleo essencial foram determinados em triplicata pelo método de microdiluição, em microplacas com 96 poços (TPP, EUA) (Rios \& Recio, 2005). As amostras foram dissolvidas em dimetilsulfóxido (DMSO, Synth, São Paulo, Brasil; $8000 \mu \mathrm{g} \cdot \mathrm{mL}^{-1}$ ), seguido da diluição em caldo de soja tríptica (Difco, Detroit, MI, EUA) para bactérias aeróbias e Schaedler Caldo (Difco), suplementado com hemina $\left(5,0 \mu \mathrm{g} \cdot \mathrm{mL}^{-1}\right)$ e vitamina $\mathrm{K}\left(10,0 \mu \mathrm{g} \cdot \mathrm{mL}^{-1}\right)$ para as bactérias anaeróbias, com a finalidade de atingir concentrações variando de 400 a 12,5 $\mu \mathrm{g} \cdot \mathrm{mL}^{-1}$. A concentração de DMSO final foi de $4 \%(v / v)$, e esta solução foi usada como controle negativo. O inóculo foi ajustado para cada organismo a fim se obter uma concentração de células de 5 $\times 10^{5}$ unidades formadoras de colônias por $\mathrm{mL}$, de acordo com o National Committee for Clinical Laboratory Standard (NCCLS) (NCCLS, 2003). O dicloridrato de clorexidina (DCC, Sigma, Poole, Dorset, Reino Unido) foi utilizado como controle positivo, e as concentrações variaram de 0,0115 $\mu \mathrm{g} \cdot \mathrm{mL}^{-1}$ a $5,9 \mu \mathrm{g} \cdot \mathrm{mL}^{-1}$. Foram realizados os controles de esterilidade dos caldos TSB e SCHAEDLER, esterilidade do dicloridrato de clorexidina, esterilidade da amostra, controle da cultura (inóculo) e o controle do DMSO. As microplacas (96 poços) com os microorganismos aeróbios foram fechados com um vedante de placa estéril e incubados aerobicamente a $37^{\circ} \mathrm{C}$ durante $24 \mathrm{~h}$. Os microrganismos anaeróbios foram fechados com um vedante de placa estéril e incubados de 48 a 72 horas numa câmara anaeróbia (Don Whitley Scientific, Bradford, Reino Unido), com $5 \%$ a $10 \%$ de $\mathrm{H}_{2}, 10 \%$ de $\mathrm{CO}_{2}, 80 \%$ a $85 \%$ de $\mathrm{N}_{2}$, a $37^{\circ} \mathrm{C}$. Logo depois, resazurina (Sigma, $30 \mu \mathrm{L}$ ) em solução aquosa $(0,01 \%)$ foi adicionada para indicar viabilidade de microorganismos. Os valores de CIM foram determinados a partir da concentração mais baixa do óleo essencial, capaz de inibir o crescimento de micro-organismos.

\section{Atividade antioxidante}

A atividade antioxidante foi avaliada pelo método da capacidade sequestrante do radical 2,2-difenil-1-picril-hidrazina (DPPH). Foram preparadas soluções etanólicas de 0,5 a 10 g.L1 de DPPH para todo o ensaio. As leituras das absorbâncias foram realizadas após 60 minutos da adição de $0,1 \mathrm{~mL}$ da solução de óleo essencial em diferentes concentrações e $3,9 \mathrm{~mL}$ da solução de DPPH $(0,06 \mathrm{mM})$ em espectrofotômetro digital de UV-Vis marca Bel Engineering modelo UV-M51 no comprimento de onda de $515 \mathrm{~nm}$, em cubeta de quartzo. Os resultados foram expressos em $\mathrm{CE}_{50}$ $\mu \mathrm{g} \cdot \mathrm{mL}^{-1}$ (quantidade de amostra necessária para reduzir em $50 \%$ a concentração inicial do radical DPPH) (Mensor et al., 2001; Oliveira, 2015).

\section{RESULTADOS E DISCUSSÃO}

As folhas frescas de C. adamantium apresentou teor de umidade de $67 \%$. Para os sete tempos de secagem estudados $(0,25 ; 0,50 ; 1 ; 3 ; 5$; 8 e 16 dias) suas umidades foram reduzidas sob temperatura do ar de $40{ }^{\circ} \mathrm{C}$ para 40,$0 ; 28,0 ; 15,0$; 9,6; 8,0; 7,6 e 4,3\% respectivamente.

$\mathrm{Na}$ tabela 1 são apresentados os teores de óleo essencial extraídos das folhas da espécie C. adamantium, quando submetidas a diferentes tempos de secagem em estufa a $40^{\circ} \mathrm{C}$ e a sombra.

A análise de variância mostrou o efeito tanto do método (secagem em estufa e a sombra) como dos tempos de secagem, bem como o da interação entre eles, sobre o teor de óleo essencial extraído. O maior teor de óleo essencial de $C$. adamantium foi obtido das folhas frescas $(0,5 \% /$ Tempo 0$)$. Os resultados para os tempos de secagem em estufa das folhas de $C$. adamantium diferiram no teor do óleo essencial extraído e em comparação 
TABELA 1. Teores médios de óleo essencial (\%) das folhas de $C$. adamantium em função de dois métodos e sete tempos de secagem.

\begin{tabular}{ccccccccc}
\hline & \multicolumn{7}{c}{ Tempos de secagem (dias) } \\
\cline { 2 - 9 } & 0 & 0,25 & 0,5 & 1 & 3 & 5 & 8 & 16 \\
\hline Estufa & $0,5 \mathrm{aA}$ & $0,49 \mathrm{aA}$ & $0,49 \mathrm{aA}$ & $0,36 \mathrm{aC}$ & $0,47 \mathrm{aA}$ & $0,37 \mathrm{bBC}$ & $0,44 \mathrm{aAB}$ & $0,47 \mathrm{aA}$ \\
Sombra & $0,47 \mathrm{aA}$ & $0,41 \mathrm{bABC}$ & $0,38 \mathrm{bBC}$ & $0,35 \mathrm{aC}$ & $0,40 \mathrm{bABC}$ & $0,44 \mathrm{aAB}$ & $0,42 \mathrm{aABC}$ & $0,48 \mathrm{aA}$
\end{tabular}

*Médias seguidas da mesma letra, minúscula na coluna e maiúscula na linha, não diferem entre si, a $5 \%$ de probabilidade pelo teste de Tukey. $\mathrm{CV}(\%)=7,33$.

com dados já descritos na literatura, os mesmos apresentaram-se semelhantes aos resultados encontrados no estudo do teor de óleo essencial das folhas in natura da espécie Campomanesia pubescens (Rocha, 2011).

$\mathrm{Na}$ secagem em estufa, os tratamentos de 1 e 5 dias diferiram estatisticamente no teor de óleo essencial das folhas in natura, já na secagem a sombra diferiram os tratamentos de 0,5 e 1 dia de secagem, variando muito pouco o teor de óleo essencial nos processos observados.

No trabalho realizado por Santos \& Inneco (2003), a secagem de folhas de erva-cidreira em duas épocas do ano, período seco e chuvoso, e secagem em secador natural com sete períodos de secagem $(0,2,4,6,8,12$ e 16 dias) constataram que, nas duas épocas, o rendimento foi crescente até atingir seu máximo aos quatro dias de secagem, obtendo-se 12,6 mL.kg-1 na estação chuvosa e 18,8 $\mathrm{mL} . \mathrm{kg}^{-1}$ na estação seca, a partir daí decresceu até o $16^{\circ} \mathrm{dia}$, quando os teores de óleo essencial foram os menores obtidos, 4,1 e 14,2 mL.kg-1 nas estações chuvosa e seca, respectivamente.

Em trabalho realizado com as folhas de assa peixe (Vernonia polyanthes) demonstrou-se que o método de secagem a sombra foi o que apresentou maior teor de óleo essencial (Corrêa et al., 2004). É descrito também, a influência do processamento da folha e do tipo de secagem sobre o teor de óleo essencial de manjericão (Ocimum basilicum) em que observou-se que a secagem em estufa apresentou maior teor de óleo essencial em relação ao material vegetal submetido a secagem com desumidificador (Rosado et al., 2011). Desta forma, fica evidente que os diferentes tempos e métodos de secagem já reportados mostram diferentes resultados quanto ao teor de óleos essenciais.

Os resultados das análises da composição química do óleo essencial das folhas de $C$. adamantium submetidas à secagem em estufa e à sombra, em diferentes tempos de secagem podem ser verificados nas tabelas 2 e 3 .

Foram identificados no óleo essencial após a secagem artificial em estufa e natural à sombra das folhas de C. adamantium 35 e 34 compostos respectivamente, dado semelhante ao encontrado por Vallilo et al., (2006a) no estudo da composição química do óleo essencial dos frutos de C. adamantium.

O óleo essencial das folhas de $C$. adamantium apresentou predominantemente sesquiterpenos, sendo que os sesquiterpenos espatulenol (1), óxido cariofileno (2) e germacreno-B (3) (Figura 1) foram os constituintes majoritários, na maioria das procedências avaliadas.

Os monoterpenos $\alpha$-pineno, $\beta$-pineno, o-cimeno e $D$-limoneno encontrados no óleo essencial de folhas de $C$. adamantium já foram identificados no óleo essencial dos frutos de $C$. adamantium por Vallilo et al., (2006b). Alguns estudos indicam que o $\beta$-pineno, juntamente com $\alpha$-pineno e outros terpenos, é citotóxico, lipofílico, bactericida, fungicida, inseticida, anticarcinogênico, pesticida, antioxidante e sedativo (Mencier et al., 2009).

As concentrações relativas do germacreno- $B$ $(27,23 \%)$ e do $\beta$-copaeno $(8,82 \%)$ sofreram um aumento considerável quando as folhas foram submetidas ao $16^{\circ}$ dia de secagem, sendo observado desta forma que suas proporções relativas foram maiores no $16^{\circ}$ dia em relação aos outros tempos de secagem estudados. Por outro lado, o espatulenol e óxido cariofileno apresentaram uma menor ocorrência no $16^{\circ}$ dia de secagem, observando-se que na secagem em estufa apresentaram $7,16 \%$ e $7,26 \%$ e à sombra $6,84 \%$ e $7,11 \%$ respectivamente. No presente estudo, o sesquiterpeno espatulenol apresentou aumento até $05^{\circ}$ dia de secagem, ocorrência semelhante à encontrada por Silva et al., (2010) que, ao estudar a influência do processamento pós-colheita e armazenamento sobre a composição química do óleo essencial de carqueja, verificou o aumento do teor deste sesquiterpeno oxigenado em consequência do armazenamento.

De acordo com Melo et al., (2004), os processos de secagem podem propiciar a transformação e/ou degradação dos constituintes químicos de óleos essenciais. Isto é observado quando o teor médio de óleo essencial de menta 
TABELA 2. Composição química do óleo essencial das folhas de $C$. adamantium submetidas a sete tempos de secagem em estufa e in natura.

\begin{tabular}{|c|c|c|c|c|c|c|c|c|c|}
\hline \multirow{2}{*}{ Compostos } & \multirow[t]{2}{*}{$\mathrm{IR}$} & \multicolumn{8}{|c|}{ Tempos de secagem (dias) } \\
\hline & & 0,00 & 0,25 & 0,50 & 1,00 & 3,00 & 5,00 & 8,00 & 16,0 \\
\hline \multicolumn{10}{|c|}{ Monoterpenos hidrocarbonados (\%) } \\
\hline a-pineno & 926 & - & - & - & - & - & - & - & 0,66 \\
\hline$\beta$-pineno & 954 & 0,05 & - & 0,10 & 0,09 & - & - & - & 0,45 \\
\hline o-cimeno & 988 & 0,13 & 0,08 & 0,13 & 0,12 & 0,03 & - & 0,07 & 0,31 \\
\hline D-limoneno & 991 & 0,56 & 0,37 & 0,66 & 0,65 & 0,25 & 0,05 & 0,34 & 2,14 \\
\hline \multicolumn{10}{|c|}{ Monoterpenos oxigenados (\%) } \\
\hline Eucaliptol & 994 & 0,39 & 0,09 & 0,12 & 0,44 & 0,04 & 0,02 & 0,06 & 0,28 \\
\hline Linalol & 1053 & 3,00 & 3,54 & 4,18 & 3,29 & 3,66 & 2,03 & 3,50 & 3,16 \\
\hline Fenchol & 1066 & 1,25 & 0,84 & 1,00 & 1,25 & 0,96 & 0,46 & 1,01 & 0,97 \\
\hline Camphol & 1118 & 2,16 & 1,47 & 1,74 & 2,07 & 1,77 & 1,12 & 1,90 & 1,70 \\
\hline Terpinen-4-ol & 1130 & 0,52 & 0,19 & 0,38 & 0,47 & 0,30 & 0,16 & 0,30 & 0,28 \\
\hline$\alpha$-Terpineol & 1144 & 4,89 & 3,13 & 3,63 & 4,83 & 3,49 & 2,31 & 3,46 & 2,96 \\
\hline Mirtenol & 1150 & 0,13 & - & - & 0,37 & - & - & - & - \\
\hline \multicolumn{10}{|c|}{ Sesquiterpenos hidrocarbonados (\%) } \\
\hline ס-elemeno & 1298 & 0,08 & - & 0,07 & - & 0,06 & 0,17 & 0,07 & 0,09 \\
\hline a-Copaeno & 1339 & 1,19 & 0,80 & 0,77 & 0,90 & 0,88 & 0,89 & 0,83 & 0,79 \\
\hline$\beta$-Elemeno & 1356 & 0,48 & 0,48 & 0,69 & 0,20 & 0,62 & 1,24 & 0,75 & 0,84 \\
\hline a-Gurjuneno & 1374 & 0,25 & 0,18 & 0,19 & 0,19 & 0,18 & 0,19 & 0,22 & 0,26 \\
\hline$\beta$-Cariofileno & 1384 & 5,95 & 6,25 & 5,14 & 5,88 & 4,96 & 6,86 & 5,59 & 6,44 \\
\hline Isoledeno & 1394 & 0,15 & - & - & 0,14 & - & - & - & 0,14 \\
\hline Aromadendreno & 1404 & 3,76 & 2,34 & 2,52 & 1,89 & 2,44 & 3,14 & 2,62 & 2,31 \\
\hline a-guaieno & 1409 & - & - & 0,09 & - & 0,10 & - & - & 0,13 \\
\hline Humuleno & 1419 & 1,32 & 1,39 & 1,29 & 1,94 & 1,29 & 1,60 & 1,38 & 1,41 \\
\hline Alloaromadendreno & 1427 & 2,12 & 1,82 & 1,75 & 2,27 & 2,00 & 2,09 & 1,94 & 1,77 \\
\hline Y-Muuroleno & 1443 & 0,83 & 0,64 & 0,60 & 0,64 & 0,68 & 0,72 & 0,77 & 0,60 \\
\hline$\beta$-copaeno & 1447 & 4,48 & 7,89 & 5,45 & 1,53 & 6,20 & 1,96 & 4,62 & 8,82 \\
\hline$\beta$-Eudesmeno & 1453 & 0,28 & 0,23 & 0,23 & 0,28 & 0,28 & 0,44 & 0,25 & 0,29 \\
\hline Germacreno B & 1464 & 18,88 & 23,66 & 22,31 & 21,66 & 21,17 & 9,35 & 18,69 & 27,23 \\
\hline a-Muuroleno & 1467 & 0,37 & 0,34 & 0,33 & 0,37 & 0,40 & 0,57 & 0,45 & 0,27 \\
\hline Y-Cadineno & 1481 & 0,95 & 0,78 & 0,76 & 0,82 & 0,76 & 1,03 & 0,83 & 0,74 \\
\hline$\delta$-Cadineno & 1490 & 1,81 & 1,56 & 1,57 & 1,14 & 1,51 & 1,16 & 1,54 & 2,15 \\
\hline Guaia-1(10),11-dieno & 1523 & 0,23 & 0,71 & 0,67 & 0,56 & 0,66 & 0,28 & 0,32 & 0,83 \\
\hline \multicolumn{10}{|c|}{ Sesquiterpenos oxigenados (\%) } \\
\hline Epiglobulol & 1525 & 0,75 & 0,18 & 0,21 & 0,27 & 0,17 & 0,46 & 0,31 & 0,21 \\
\hline Espatulenol & 1544 & 11,63 & 10,89 & 11,78 & 14,94 & 13,12 & 21,76 & 14,72 & 7,16 \\
\hline Oxido cariofileno & 1550 & 9,65 & 8,48 & 9,12 & 11,93 & 8,76 & 12,28 & 9,70 & 7,26 \\
\hline Viridiflorol & 1557 & 2,71 & 2,60 & 2,91 & 2,69 & 2,69 & 3,45 & 2,99 & 2,38 \\
\hline Guaiol & 1559 & 1,25 & 1,11 & 1,23 & 1,15 & 1,25 & 1,34 & 1,28 & 1,08 \\
\hline$\delta$-cadinol & 1605 & 1,49 & 1,67 & 1,90 & 1,58 & 1,82 & 2,02 & 1,96 & 1,80 \\
\hline a cadinol & 1617 & 2,11 & 2,23 & 2,51 & 2,44 & 2,29 & 3,11 & 2,54 & 2,06 \\
\hline Monoterpenos & & 13,08 & 9,71 & 11,94 & 13,58 & 10,50 & 6,15 & 10,64 & 12,91 \\
\hline Sesquiterpenos & & 72,72 & 76,23 & 74,09 & 75,41 & 74,29 & 76,11 & 74,37 & 77,06 \\
\hline Total de compostos & & 34 & 30 & 33 & 33 & 32 & 30 & 31 & 35 \\
\hline
\end{tabular}

IR - Índice de retenção.

reduz de 1 a $0,12 \%$ em temperaturas de 40 a $80^{\circ} \mathrm{C}$ e redução para o óleo essencial de alecrim $(2,13$ a $1,09 \%)$ nas mesmas condições.

A atividade antibacteriana do óleo essencial das folhas de $C$. adamantium também foi avaliada frente a algumas bactérias orais, como apresentado na tabela 4.

O óleo essencial estudado apresentou moderada atividade inibitória frente a todas as bactérias testadas. Valores de CIM inferior a 100 $\mu \mathrm{g} \cdot \mathrm{mL}^{-1}$ tem atividade antibacteriana considerada boa; de 100 a $500 \mu \mathrm{g} . \mathrm{mL}^{-1}$ moderada; de 500 a 1000 
TABELA 3. Composição química do óleo essencial das folhas de $C$. adamantium submetidas a sete tempos de secagem à sombra e in natura.

\begin{tabular}{|c|c|c|c|c|c|c|c|c|c|}
\hline \multirow[t]{2}{*}{ Compostos } & \multirow[t]{2}{*}{$\overline{I R}$} & \multicolumn{8}{|c|}{ Tempos de secagem (dias) } \\
\hline & & 0,00 & 0,25 & 0,50 & 1,00 & 3,00 & 5,00 & 8,00 & 16,0 \\
\hline \multicolumn{10}{|c|}{ Monoterpenos hidrocarbonados (\%) } \\
\hline a-pineno & 926 & - & - & - & - & - & - & - & 1,00 \\
\hline$\beta$-pineno & 954 & 0,14 & 0,15 & 0,10 & 0,08 & 0,04 & - & 0,18 & 1,36 \\
\hline o-cimeno & 988 & 0,07 & 0,16 & 0,12 & 0,14 & 0,09 & 0,02 & 0,17 & 0,28 \\
\hline D-limoneno & 991 & 0,57 & 0,74 & 0,50 & 0,96 & 0,40 & 0,18 & 0,78 & 2,09 \\
\hline \multicolumn{10}{|c|}{ Monoterpenos oxigenados (\%) } \\
\hline Eucaliptol & 994 & 0,33 & 0,21 & 0,17 & 0,48 & 0,15 & 0,05 & 0,17 & 0,38 \\
\hline Linalol & 1053 & 3,00 & 4,32 & 4,81 & 4,28 & 4,20 & 3,83 & 4,47 & 4,08 \\
\hline Fenchol & 1066 & 1,25 & 1,22 & 1,30 & 1,30 & 1,19 & 1,00 & 1,27 & 1,12 \\
\hline Camphol & 1118 & 2,16 & 2,02 & 2,23 & 2,14 & 2,10 & 1,88 & 2,21 & 1,79 \\
\hline Terpinen-4-ol & 1130 & 0,42 & 0,42 & 0,44 & 0,51 & 0,43 & 0,40 & 0,45 & 0,44 \\
\hline$\alpha$-Terpineol & 1144 & 4,84 & 4,20 & 4,76 & 4,94 & 4,42 & 3,74 & 4,23 & 3,42 \\
\hline Mirtenol & 1150 & 0,20 & - & - & 0,30 & 0,08 & - & 0,11 & - \\
\hline \multicolumn{10}{|c|}{ Sesquiterpenos hidrocarbonados (\%) } \\
\hline ס-elemeno & 1298 & 0,10 & 0,06 & 0,06 & - & - & 0,08 & 0,09 & 0,05 \\
\hline a-Copaeno & 1339 & 1,19 & 0,89 & 0,72 & 0,54 & 0,84 & 0,93 & 0,85 & 0,83 \\
\hline$\beta$-Elemeno & 1356 & 0,67 & 0,52 & 0,52 & 0,30 & 0,53 & 0,92 & 0,62 & 0,51 \\
\hline a-Gurjuneno & 1374 & 0,31 & 0,28 & 0,23 & 0,15 & 0,23 & 0,20 & 0,31 & 0,23 \\
\hline$\beta$-Cariofileno & 1384 & 5,95 & 4,90 & 4,49 & 4,86 & 4,71 & 4,53 & 4,55 & 4,72 \\
\hline Isoledeno & 1394 & 0,19 & 0,20 & 0,13 & - & - & 0,24 & 0,23 & 0,17 \\
\hline Aromadendreno & 1404 & 3,76 & 2,99 & 2,68 & 1,95 & 2,74 & 3,25 & 2,90 & 2,66 \\
\hline a-guaieno & 1409 & 0,12 & - & 0,12 & - & 0,12 & - & - & - \\
\hline Humuleno & 1419 & 1,32 & 1,26 & 1,17 & 1,66 & 1,18 & 1,25 & 1,21 & 1,18 \\
\hline Alloaromadendreno & 1427 & 2,12 & 1,97 & 1,73 & 1,92 & 1,85 & 2,22 & 1,89 & 1,85 \\
\hline Y -Muuroleno & 1443 & 0,83 & 0,92 & 0,78 & 0,63 & 0,72 & 0,91 & 0,77 & 0,56 \\
\hline$\beta$-copaeno & 1447 & 4,48 & 5,65 & 4,57 & 0,92 & 5,11 & 2,33 & 4,59 & 8,05 \\
\hline$\beta$-Eudesmeno & 1453 & 0,40 & 0,36 & 0,34 & 0,23 & 0,38 & 0,41 & 0,29 & 0,28 \\
\hline Germacreno B & 1464 & 18,89 & 19,29 & 18,26 & 18,75 & 19,38 & 10,79 & 17,59 & 27,86 \\
\hline a-Muuroleno & 1467 & 0,53 & 0,42 & 0,36 & 0,43 & 0,36 & 0,42 & 0,38 & 0,37 \\
\hline y-Cadineno & 1481 & 0,95 & 0,82 & 0,77 & 0,53 & 0,81 & 0,90 & 0,79 & 0,69 \\
\hline$\delta$-Cadineno & 1490 & 1,81 & 1,53 & 1,53 & 0,92 & 1,58 & 1,12 & 1,47 & 2,02 \\
\hline Guaia-1(10),11-dieno & 1523 & 0,33 & 0,33 & 0,26 & 0,13 & 0,32 & 0,23 & 0,27 & 0,64 \\
\hline \multicolumn{10}{|c|}{ Sesquiterpenos oxigenados (\%) } \\
\hline Epiglobulol & 1525 & 0,75 & 0,37 & 0,78 & 0,34 & 0,71 & 0,43 & 0,48 & 0,28 \\
\hline Espatulenol & 1544 & 11,63 & 12,55 & 11,35 & 14,27 & 11,77 & 20,64 & 13,72 & 6,84 \\
\hline Oxido cariofileno & 1550 & 9,65 & 8,81 & 10,24 & 9,50 & 9,87 & 11,34 & 9,52 & 7,11 \\
\hline Viridiflorol & 1557 & 2,71 & 2,73 & 3,19 & 2,74 & 2,96 & 3,18 & 2,94 & 2,44 \\
\hline Guaiol & 1559 & 1,25 & 1,27 & 1,47 & 1,15 & 1,44 & 1,40 & 1,40 & 1,10 \\
\hline$\delta$-cadinol & 1605 & 1,49 & 1,64 & 2,02 & 1,33 & 1,77 & 1,81 & 1,86 & 1,61 \\
\hline a cadinol & 1617 & 2,11 & 2,09 & 2,66 & 2,47 & 2,54 & 2,64 & 2,48 & 1,87 \\
\hline Monoterpenos & & 12,98 & 13,44 & 14,43 & 15,13 & 13,10 & 11,10 & 14,04 & 15,96 \\
\hline Sesquiterpenos & & 73,54 & 71,85 & 70,43 & 65,72 & 71,92 & 72,17 & 71,20 & 73,92 \\
\hline Total de compostos & & 35 & 33 & 34 & 32 & 33 & 32 & 34 & 34 \\
\hline
\end{tabular}

IR - Índice de retenção.

$\mu \mathrm{g} \cdot \mathrm{mL}^{-1}$ fraca e acima de $1000 \mu \mathrm{g} \cdot \mathrm{mL}^{-1}$ inativa (Holetz et al., 2002; Ayres et al., 2008).

Este resultado pode ser explicado pela presença de metabólitos secundários, como monoterpenos e sesquiterpenos. Vários mecanismos são propostos para explicar a atividade antimicrobiana dos óleos essenciais. Entende-se que a inibição do crescimento microbiano pela ação de óleos essenciais é devida ao dano direto causado à integridade da membrana celular pelos componentes lipofílicos do óleo essencial, o que afeta diretamente a manutenção do $\mathrm{pH}$ celular 


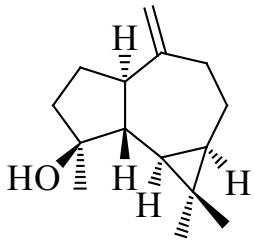

1

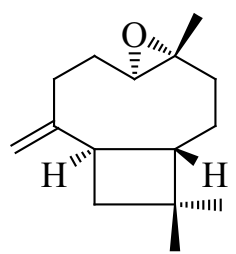

2

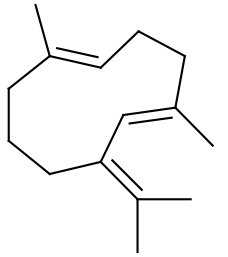

3

FIGURA 1. Representação estrutural dos componentes majoritários presentes no óleo essencial de folhas de C. adamantium na maioria das procedências avaliadas.

e o equilíbrio de íons inorgânicos. Em adição, é reportada a perda de conteúdo celular, como lipídios e proteínas, em função de alguns componentes de óleos essenciais sobre bactérias Gram-positivas e Gram-negativas. Destaca-se ainda, que o risco de micro-organismos patogênicos desenvolverem resistência aos óleos essenciais é muito baixo, é esta é uma característica vantajosa dos óleos essenciais sobre outros agentes antimicrobianos, pois pode trazer benefícios nas diversas áreas passíveis de aplicação (Peter, 2004; Oyedemi et al., 2009; Rahman et al., 2009).

Dentre os compostos identificados no óleo essencial de folhas de C. adamantium, o sesquiterpeno espatulenol é dígno de menção, visto que além de influenciar no aroma de muitos óleos de interesse comercial para a indústria de perfumes, possui propriedade antibacteriana e moderada atividade citotóxica frente células do tipo KB (Chinou et al., 1996; Santos et al., 2012; Limberger et al., 2004)

Em relação ao ensaio de verificação do sequestro do radical livre DPPH observou-se um $\mathrm{CE}_{50}=740,0 \mu \mathrm{g} \cdot \mathrm{mL}^{-1}$ para óleo essencial de folhas de C. adamantium. Comparando-se o valor de $\mathrm{CE}_{50}$ obtido para o óleo essencial de folhas de $C$. adamantium com o padrão quercetina $\left(\mathrm{CE}_{50}=3,13\right.$ $\mu \mathrm{g} . \mathrm{mL}^{-1}$ ) utilizado, comprova-se seu baixo potencial antioxidante (Tabela 5).

O potencial antioxidante de óleos essenciais tem sido bastante estudado (Simionatto et al., 2007) e a baixa atividade antioxidante demonstrada pelo óleo essencial de folhas de $C$. adamantium pode ser explicada pela baixa concentração de compostos com este potencial. O mesmo não possui em sua composição compostos com reconhecida atividade antioxidante em quantidades significativas, exceto a presença de $\beta$-cariofileno que associado com compostos fenólicos têm seu potencial antioxidante aumentado através do efeito sinérgico (Shahidi et al., 1992).

\section{CONCLUSÃO}

Ao avaliar o efeito de dois métodos e sete tempos de secagem das folhas de $C$. adamantium sobre o óleo essencial conclui-se que houve influência dos dois métodos utilizados bem como dos tempos de secagem. Os teores de óleo essencial nos tempos de 1 e 5 dias de secagem em estufa diferiram estatisticamente, já na secagem a sombra os tratamentos que diferiram estatisticamente foram

TABELA 4. Efeito inibidor do óleo essencial de folhas de C. adamantium frente a bactérias aeróbias e anaeróbias.

\begin{tabular}{|c|c|c|c|}
\hline & Micro-organismos & $\begin{array}{l}\text { Concentração Inibitória } \\
\text { Mínima }(\mathrm{CIM})-\mu \mathrm{g} \cdot \mathrm{mL}^{-1}\end{array}$ & $\begin{array}{c}\text { Dicloridrato de } \\
\text { clorexidina - } \\
\mu \mathrm{g} \cdot \mathrm{mL}^{-1} \text { (controle } \\
\text { positivo) }\end{array}$ \\
\hline & $\begin{array}{l}\text { Streptococcus mutans } \\
\text { (ATCC 25175) }\end{array}$ & 400 & 0,922 \\
\hline & $\begin{array}{l}\text { Streptococcus mitisa } \\
\text { (ATCC 49456) }\end{array}$ & 100 & 1,844 \\
\hline Aeróbios & $\begin{array}{l}\text { Streptococcus sanguinisa } \\
\text { (ATCC 10556) } \\
\text { Streptococcus sobrinusa }\end{array}$ & 200 & 0,922 \\
\hline Anaeróbio & $\begin{array}{c}\text { (ATCC 33478) } \\
\text { Bacteroides fragilis }^{b} \\
\quad(\text { ATCC 25285) }\end{array}$ & 400 & 0,737 \\
\hline
\end{tabular}

aBactéria gram-positiva; 'Bactéria gram-negativa 
TABELA 5. Resultados dos ensaios das atividades antioxidantes (DPPH) do óleo essencial de folhas de $C$. Adamantium (CA = Campomanesia adamantium)

\begin{tabular}{cll}
\hline Ensaio & CA (Folhas) & Quercetina \\
\hline Atividade antioxidante $\left(\mu \mathrm{g} \cdot \mathrm{mL}^{-1}\right)$ & 740,0 & 3,13 \\
\hline
\end{tabular}

de 0,5 e 1 dia. Ao analisar os métodos de secagem, os tempos $0,25,0,50,3$ e 5 dias diferiram entre si, os demais foram estatisticamente iguais, porém nos tempos $0,25,0,50$, e 3 dias a secagem em estufa apresentou teores maiores de óleo essencial em relação a secagem à sombra.

Através das análises de cromatografia gasosa acoplada à espectrometria de massas, foram identificados 35 e 34 compostos no óleo essencial de folhas $C$. adamantium submetidas à secagem em estufa e a sombra respectivamente, sendo os sesquiterpenos espatulenol, óxido cariofileno e o germacreno-B os constituintes majoritários na maioria das procedências realizadas. Os métodos de secagem influenciaram no aumento da concentração relativa apresentada pelos sesquiterpenos germacreno-B e $\beta$-copaeno e também na diminuição da concentração relativa do espatulenol e do óxido cariofileno no $16^{\circ}$ dia de secagem.

A análise da atividade antibacteriana demonstrou que o óleo essencial estudado apresenta moderada atividade frente às bactérias Streptococcus mitis, Streptococcus mutans, Streptococcus sanguinis, Streptococcus sobrinus e Bacteroides fragilis.

Através do ensaio da atividade antioxidante (DPPH), verificou-se que a concentração ativa foi alta, sendo superior a $700 \mu \mathrm{g} / \mathrm{mL}$. Desta forma, fica evidenciada a baixa atividade antioxidante do óleo essencial de folhas de $C$. adamantium, fato diretamente relacionado à baixa concentração de metabólitos secundários capazes de reagir e neutralizar os radicais livres.

\section{REFERÊNCIA}

ADAMS, R.P. Identification of essential oil componentes by gas chromatography quadrupole mass spectroscopy, 4ed. , Allured: Card Stream I L, 2001, 469p.

SILVA, F.A.S.; AZEVEDO, C.A.V. Versão do programa computacional ASSISTAT para o sistema operacional Windows. Revista Brasileira de Produtos Agroindustriais, v. 4, n.1, p.71-78,2002.

AYRES, M.C.C. et al. Atividade antibacteriana de plantas úteis e constituintes químicos da raiz de Copernicia prunifera. Revista Brasileira de Farmacognosia, v.18, n.1, p.90-97, 2008.

COUTINHO, I.D. Estudo químico e atividades biológicas de Campomanesia adamantium (Cambess.) O. Berg
(Myrtaceae). 2008. 159p. Dissertação (Mestrado em Química, área de concentração química orgânica), Programa de Pós-graduação em Química, Universidade Federal de Mato Grosso do Sul, Campo Grande-MS.

COUTINHO, I.D. et al. Identification of the volatile compounds of leaves and flowers in Guavira (Campomanesia adamantium O. Berg). Journal Essential Oil Research, v.20, n.5, p.405-407, 2011.

CORRÊA, R.M. et al. Rendimento de óleo essencial e caracterização organoléptica de folhas de assa-peixe submetidas a diferentes métodos de secagem. Ciência e agrotecnologia, v.28, n.2, p.339-344, 2004.

CHINOU, I.B. et al. Chemical and biological studies on two elichrysum species of Greek origin. Planta Medica, v.62, n.4, p.377-379, 1996.

D'ANGELIS, A.S.R. et al. Pimenta pseudocaryophyllus (Gomes) Landrum: aspectos botânicos, ecológicos, etnobotânicos e farmacológicos. Revista Brasileira de Plantas Medicinais, v.16, n.3, p.607-617, 2014.

GOGOSZ, A.M. et al. Morfoanatomia da plântula de Campomanesia Xanthocarpa O. Berg. (Myrtaceae). Acta Botanica Brasilica, v.24, n.3, p.613-623, 2010.

HOLETZ, F.B. et al. Screening of some plants used in the Brasilian folk medicine for the treatment of infectious diseases. Memórias do Instituto Oswaldo Cruz, v.97, n.7, p.1027-1031, 2002.

LIMA, M.E.L. et al. Antimicrobial activity of the essential oil from two specimens of Pimenta pseudocaryophyllus (Gomes) L. R. Landrum (Myrtaceae) native from São Paulo state - Brazil. Pharmacologyonline, v.3, p.589593, 2006.

LIMBERGER, R.P. et al. Óleos voláteis de espécies de Myrcia nativas do Rio Grande do Sul. Química Nova, v.27, n.6, p.916-919, 2004.

LORENZI, H.; BACHER, L.; LACERDA, M.; SARTORI, $S$. Frutas brasileiras e exóticas cultivadas (de consumoin natura). 1ed. , São Paulo: Instituto Plantarum de Estudos da Flora, 2006. 672p.

MACHADO, M.P. et al. Efeito da secagem natural e artificial da biomassa foliar de Piper hispidinervum na composição química do óleo essencial. Semina, v.34, n.1, p.265-270, 2013.

MAIA, J.G.S. et al. Espécies de Piper da Amazônia ricas em safrol. Química Nova, v.10, n.3, p.200-204, 1987.

MELO, E.C. et al. Influência do processo de secagem na qualidade de plantas medicinais, revisão. Engenharia na Agricultura, v.12, n.4, p.307-315, 2004.

MENCIER, B. et al. The essential oil of turpentine and its major volatile fraction ( $\alpha$ - and $\beta$-pinenes): a review. International journal of Occupational Medicine and Environmental Health, v.22, n.4, p.331-342, 2009.

MENSOR, L.L. et al. Screnning of Brazilian plant extracts for antioxidant activity by the use of DPPH free radical method. Phytotherapy Research,v.15, n.2, p.127-130, 2001.

NCCLS. The National Committee for Clinical Laboratory 
Standards. The Methods for Dilution Antimicrobial Susceptibility Tests for Bacteria that Grow Aerobically; Approved Standard. 6ed. NCCLS document M7-A6. Wayne (PA): NCCLS; 2003, 87p.

OLIVEIRA, G.L.S. Determinação da capacidade antioxidante de produtos naturais in vitro pelo método do DPPH•: estudo de revisão. Revista brasileira de Plantas Medicinais, v.17, n.1, p.36-44, 2015.

OYEDEMI, S.O. et al. The proposed mechanism of bactericidal action of eugenol, $\alpha$-terpineol and $\mathrm{y}$-terpinene against Listeria monocytogenes, Streptococcus pyogenes, Proteus vulgaris and Escherichia coli. African Journal of Biotechnology, v.8, n.7, p.1280-1286, 2009.

PAULA, J.A.M. et al. Estudo farmacognóstico das folhas de Pimenta pseudocaryophyllus (Gomes) R. Landrum - Myrtaceae. Revista Brasileira de Farmacognosia, v.18, n.2, p.265-278, 2008.

PETER K.V (Ed.). Handbook of herbs and spices. 1st Edition, V.1. Cambridge: Woodhead Publishing Limited; 2004, 640p.

PIMENTEL, F.A. et al. A convenient method for the determination of moisture in aromatic plants. Química Nova, v.29, n.2, p.373-375, 2006.

RAHMAN, A. et al. Inhibition of foodborne pathogens and spoiling bacteria by essential oil extracts of Erigeron ramosus (WALT.). Journal Food Safety, v.29, n.2, p.176-189, 2009.

RIOS, J.L.; RECIO, M. Medicinal plants and antimicrobial plants. Journal of Ethnopharmacology, v.100, p.804,2005.

ROCHA, E.O. Avaliação dos constituintes fenólicos e voláteis, atividade antioxidante e antimicrobiana de Campomanesia pubescens (DC.) O. Berg (gabiroba). 2011. 82p. Dissertação (Mestrado em Química, área de concentração: química orgânica) Programa de pós graduação do Instituto de Química, da Universidade Federal de Uberlândia, Uberlândia - MG.

ROSADO, L.D.S. et al. Influência do processamento da folha e tipo de secagem no teor e composição química do óleo essencial de manjericão cv. Maria Bonita. Ciência e Agrotecnologia, v.35, n.2, p.291-296, 2011.
SANTOS, M.R.A.; INNECO, R. Influência de períodos de secagem de folhas no óleo essencial de erva-cidreira (quimiotipo limoneno-carvona). Revista Ciência Agronômica, v.34, n.1, p.5-11, 2003.

SANTOS, R.F. et al., Composição química e produtividade dos principais componentes do óleo essencial de Baccharis dracunculifolia DC. em função da adubação orgânica. Revista Brasileira de Plantas Medicinais, v.14, n. esp., p.224-234, 2012. SERAFIN, C. et al. Avaliação do potencial antimicrobiano de Plinia glomerata (Myrtaceae). Revista Brasileira de Farmacognosia, v.17, n.4, p.578-582, 2007.

SHAHIDI, F. et. al. Phenolic antioxidants. Critical Reviews in Food Science and Nutrition, v.32, n.1, p.67-103, 1992.

SILVA, F.G. et al. Influência do processamento póscolheita e armazenamento na composição química da droga vegetal e do óleo essencial de carqueja [Baccharis trimera (Less.) DC.]. Revista Brasileira de Plantas Medicinais, v.12, n.4, p.436-442, 2010.

SIMIONATTO, E. et al. Chemical composition and evaluation of antibacterial and antioxidant activities of the essential oil of Croton urucurana Baillon (Euphorbiaceae) stem bark. Journal of the Brasilian Chemical Society, v.18, n.5, p.879-885, 2007.

SIQUEIRA, C.A.T. et al. Chemical constituents of the volatil oil from leaves of Annona coriácea and in vitro antiprotozoal activity. Revista Brasileira de Farmacognosia, v.21, n.21, p.33-40, 2011.

VALLILO, M.I. et al. Identificação de terpenos no óleo essencial dos frutos de Campomanesia adamantium (Cambessédes) O. Berg- Myrtaceae. Revista do Instituto Florestal, v.18, n. único, p.15-22, 2006a.

VALLILO, M.I. et al. Composição química dos frutos de Campomanesia adamantium (Cambessédes) O. Berg. Food Science and Technology, v.26, n.4, p.805-810, 2006b.

VIEIRA, R.F.; FÁVERO, A.P.; PORTO, A.C. Frutas Nativas da Região Centro-Oeste do Brasil. 1ed. , Brasília: Embrapa Recursos Genéticos e Biotecnologia, 2006. 320p. 